\title{
Effect of Computer-Assisted Instruction (CAI) on the Academic Achievement in Secondary Physics
}

\author{
Leann Jester Daus Rosali \\ Notre Dame of Marbel University, City of Koronadal, Philippines \\ Email:ljdaus@gmail.com
}

How to cite this paper: Rosali, L.J.D. (2020) Effect of Computer-Assisted Instruction (CAI) on the Academic Achievement in Secondary Physics. Open Access Library Journal, 7: e6319.

https://doi.org/10.4236/oalib.1106319

Received: April 13, 2020

Accepted: May 22, 2020

Published: May 25, 2020

Copyright () 2020 by author(s) and Open Access Library Inc.

This work is licensed under the Creative Commons Attribution International License (CC BY 4.0).

http://creativecommons.org/licenses/by/4.0/

\section{(c) (i) Open Access}

\begin{abstract}
The study aims to determine the effect of implementing a Computer-Assisted Instruction on secondary physics students' academic achievement. The research utilized the quasi experimental pretest-posttest control group design that is participated by 157 Grade 10 students of a private school in the Philippines. The experimental group was taught using the Computer-Assisted Instruction while the control group was instructed using the conventional method of teaching Physics. Mann-Whitney test with a significance level of 0.05 was used in comparing the difference between pretest scores of the control and experimental groups, the difference between the pretest and posttest scores of the control group and experimental group, and $Z$ test with a significance level of 0.05 was utilized in comparing the mean gain scores of both groups to determine the effect of the CAI. The findings of the study show that both CAI and conventional methods of teaching improve the level of performance of students in physics significantly. However, when the effectiveness of the two methods is compared, there is no significant difference between their effects on academic achievement. Therefore, CAI could be used as an alternative teaching method.
\end{abstract}

\section{Subject Areas}

Physics Education

\section{Keywords}

Computer-Assisted Instruction, Physics Education, Secondary Education

\section{Introduction}

Despite the many educational reforms implemented, international assessments 
such as Trends in International Mathematics and Science Study (TIMSS) and Programme for International Student Assessment (PISA) have reflected the problematic state of science education worldwide (Martin, Mullis, Foy, and Stanco, 2012) [1]. In 2015, the TIMSS for Science had shown that $84 \%$ of the students from participating countries had achieved low benchmark while the PISA for science revealed that $20 \%$ of students who participated in the assessment had scored below the baseline level for proficiency in the subject. Both tests have also exposed that there is a difficulty in improving the performance in science when compared to the previous years' results (PISA 2015 Results in Focus, 2018 [2]; “TIMSS 2015 International Reports”, 2019 [3]).

For decades, Physics Education Research (PER) studies have been investigating how to improve students' learning. Among the areas underscored in investigations to promote learning were conceptual understanding, epistemology, problem-solving, attitudes, social aspects, technology, evaluation of specific instructional interventions, and development of instructional materials (Bao \& Koenig, 2019 [4]; Beichner, 2009 [5]). In the early researches, it was found out that despite formal instruction, there is still a gap between what has been taught and learned in the classroom (May, 2002) [6]. Some studies attributed the problem to the use of conventional direct instruction instead of active learning (Physics Education Research, 2009 [7]; Freedman, 1996 [8]). Hence, alternative instructional methods and strategies such as integrating technology in classroom instruction were explored for their potentiality of making learning active and independent.

Numerous foreign researches were conducted to investigate the effect of Computer-Assisted Instruction (CAI) on academic achievement and learning attitude of learners towards a subject. Some studies claim that computer-aided instruction is effective in improving students' achievement as compared to the traditional lecturing (Kara \& Kahraman, 2008 [9]; Christmann \& Badgett, 2000 [10]; Vernadakis et al., 2006 [11]; Camnalbur \& Erdogan, 2008 [12]), while some findings show that the use of CAI made students' performance essentially unchanged (Alegre, 2012 [13]; Sumadic, 2012 [14]; Guerrero, 2009 [15]; Pelones, 2003 [16]; Diculen, 1999 [17]). This study aimed to verify if the same connection will be established between CAI and academic achievement in physics across Filipino secondary students taking up physics.

\section{Objectives of the Study}

The general aim of this study was to find out the effect of Computer-Assisted Instruction on the academic performance in Physics of secondary students. It aims to 1) compare the academic performance of the control group and experimental group before instruction through their pretest scores; 2) determine if there is a significant difference in the academic achievement of the control group before and after instruction through the pretest and posttest scores; 3 ) determine if there is a significant difference in the academic achievement of the experi- 
mental group before and after instruction through the pretest and posttest scores, and 4) compare the academic achievement of the control group and experimental group through in their mean gain scores.

\section{Research Design}

This study adopted a quasi-experimental method of research to determine the effect of the CAI method and the conventional method of teaching on the academic achievement in Physics of Grade 10 secondary students. It made use of the Pretest/Posttest Non-Equivalent Groups design since the classes are already pre-existing and are randomly assigned to either the experimental group or control group through cluster sampling.

\subsection{Participants}

This study involved four (4) pre-existing, heterogeneous classes of Grade 10 students of Notre Dame of Marbel University-Integrated Basic Education Department. Of the six (6) Grade 10 classes taking up Physics course, only four (4) sections were involved in the study. The Science Curriculum class and the afternoon shift class were excluded for the reason of homogeneity. All the one hundred fifty-seven (157) Grade 10 students from the four classes were grouped into two-experimental and control groups, each composed of a varying number of students. The experimental group, composed of two pooled classes with 80 students, was taught using Computer-Assisted Instruction. On the other hand, the control group with 77 students from two combined classes was instructed using the conventional method of teaching Physics. To be assigned in the experimental group or control group, the four pre-existing classes were subjected to random selection so that each class was given an equal chance of being assigned to any of the two groupings mentioned above. Cluster sampling was used since students were already assigned in classes, and the researcher is not in a position to reorganize the classes.

\subsection{Research Instrument}

The research instruments that were used in determining the effectiveness of the CAI as a teaching method are the following:

1) Pretest and Posttest of the Benchmark/Summative Assessment of FOSS Module on Electricity and Magnetism

The Pretest and Posttest consist of 15-item open-response and multiple-choice questions. This test is given before and after the administration of the module.

This test is a part of the assessment portion of the FOSS Module on Magnetism and Electricity. The development of this test is research-based. The test items have been tested with more than 1000 students and have been proven valid and reliable.

The pretest and posttest are being scored using the embedded coding guides. Codes are provided to check the depth of learning the student has. 
2) FOSS Magnetism and Electricity Module

The FOSS Magnetism and Electricity Module is a research-based science curriculum module developed by The Regents of University of California consisting of five subsequent investigations. It covers topics on Magnetism, Electricity, Circuits, and Electromagnetism.

This module involves learning by doing through science active investigations. It is assessed through its embedded or formative assessments and Pretest/Posttest and I-Checks on Benchmark/Summative assessments.

This module also integrated reading as a language extension activity. Reading sessions allow students to relate the science concepts to real-life applications and integrate these concepts into other fields of studies through selections included in the FOSS Science Resource Audiobooks.

3) PhET Interactive Simulations

These are interactive, research-based simulations of Electricity, Magnets, and Circuits developed by the University of Colorado, Boulder. These simulations are distributed for free to help students see the connection between science and its real-life applications. It could be accessed online or be installed on computers so that it could be run offline.

\subsection{Research Procedure}

To avoid bias, only one teacher was assigned to deliver instruction to both the experimental and control groups. The following were the steps in the procedure in performing this research:

1) Preliminary Preparation

This task included the acquisition of necessary instruments, module, materials which was utilized in the study. It also included: a) seeking permission to use the FOSS Module in Magnetism and Electricity from The Regents of the University of California; and b) reviewing resource materials and checking the instruments to be used if they align with the Department of Education's (DepEd) Minimum Learning Competencies (MLC).

Consent was asked from The Regents of University of California regarding the use of the FOSS Module on Magnetism and Electricity in the study. Approval was granted, which allowed the researcher to implement the module, reprint, and improvise materials.

The module was also subjected to the review of experts, teachers, and academic coordinators of both public and private secondary schools to check if the said modules are aligned with the DepEd MLCs.

Permission to conduct research with the students was sought from the Office of the University President and the Office of the Principal of the participating school. Approval was granted to implement the study at NDMU-IBED.

2) Administer Pre-Test

The 15-item FOSS Magnetism and Electricity Pretest of Benchmark/Summative Assessment was administered to the 157 Grade 10 students. 
3) Score Pretest and Group Population

The pretest scores were determined, after which, divided the population into two groups through random cluster selection.

4) Delivery of Instruction

After forming two groups, one group was randomly assigned as the experimental group and the other as the control group. The experimental group was exposed to the CAI method while the control group to the conventional method. Both groups were given the same time duration of 55 minutes per daily session, which were instructed by the same teacher to eliminate teacher factor. The implementation of the module lasted for five (5) weeks.

a) The Experimental Group

The experimental group was instructed using the FOSS Module on Magnetism and Electricity. The module was delivered through Active Investigation sessions; Wrap Up sessions with Simulations, and Online Reading sessions.

Lessons were introduced through the following format: i) Active Investigation Sessions; ii) Wrap Up Sessions with simulations; and iii) Online Reading Sessions. Computer devices and software were utilized during the delivery of instruction.

Active Investigation (AI) sessions involved hands-on laboratory activities in discovering concepts, and develop scientific skills like observation, making inferences, and the likes. Active investigations allowed students to engage in the lesson and explore ideas on their own. Active Investigation discussions made use of overhead multimedia presentations like Microsoft PowerPoint in the Physics Laboratory. The PPTs were used as supplementary material and was used in direct instruction.

Wrap up (WU) sessions served as post laboratory discussions that summed up the findings in the Active Investigation sessions. It included learning new scientific terms/words which were added in the Word Bank and a list of essential concepts or generalizations in the Content/Inquiry Chart. Word banks and Concept/Inquiry Charts were constructed and presented using the PowerPoint presentations, which were flashed in the multimedia projector in the classrooms and laboratory.

Online Reading sessions were given after Wrap Up sessions. It allowed students to read selections about the topics covered. The selections were taken from the FOSS Science Resource Audio Books, which were transcribed and posted on an online blog. These sessions were conducted in the Computer Laboratory.

Also, PhET simulations were used during discussions in AI sessions and WU sessions to supplement the concepts learned during the hands-on laboratory activities. The simulations were presented as overheads through direct instruction instead of being individually manipulated by students.

b) The Control Group

The control group was instructed using the same module-FOSS Module on Magnetism and Electricity. The module was delivered through Active Investigation sessions; Wrap Up sessions, and Reading sessions. 
Lessons were given through the following format: i) Active Investigation Sessions; ii) Wrap Up Sessions; and iii) Reading Sessions. Computer devices and software were not utilized during the delivery of instruction.

Active Investigation sessions for the control group were the same as the hands-on laboratory activities that the experimental group performed. However, for the control group, no computer hardware and software was used during the Active Investigation sessions to aid instruction. Instead, traditional "chalk and talk" direct instruction was used.

Wrap Up sessions were conducted using the traditional use of the blackboard and chalk for making Word Banks and Concept/Inquiry Charts.

Reading sessions was also given after Wrap Up sessions. However, selections were given to students in brochure forms. Topics covered were similar to the selections provided to the experimental group. The selections were taken from the FOSS Science Resource Audio Books, which were transcribed and printed in brochures. However, there were no simulations given to this group.

5) Administer Posttest and Score Posttest

After the 5-week instruction, the 15-item FOSS Magnetism and Electricity Posttest of Benchmark/Summative Assessment was given to the students in the experimental and control groups. All other factors were kept the same for both groups to avoid other influences in their test performance.

The scores were coded, tabulated, and analyzed.

\subsection{Statistical Treatment}

To determine the appropriate statistical instrument to use, tests for Normality were undertaken.

A non-parametric test known as Mann-Whitney Test was utilized to find the following: 1) significant difference in the pretest scores of experimental and control groups; 2) significant difference in the pretest and posttest scores of the control group; and 3) significant difference in the pretest and posttest scores of the experimental group since tests for Normality showed that either or both pretest and posttest scores of experimental and control groups is/are not normally distributed.

A parametric test known as the $Z$ Test was utilized to find the significant difference between the mean gain scores of the experimental and control groups since both variables are normally distributed.

\section{Results and Discussion}

1) Difference between Pretest Scores of the Experimental and Control Groups

A non-parametric test was used to determine the difference between the pretest scores of the experimental and control groups. Table 1 shows the result of the Mann-Whitney test.

Table 1 shows that there is no significant difference between the pretest scores of the experimental and control groups, as indicated by the p-value of 0.371 , 
which is greater than the significance level alpha (0.05). Hence, one cannot reject the null hypothesis $H_{o}$. This means that the experimental and control groups have the same performance level before classroom instruction.

2) Difference between the Pretest and Posttest Scores of the Control Group

The difference between the pretest and posttest scores of the control group was statistically tested with the Mann-Whitney test to determine the effectiveness of the conventional method of teaching. Findings obtained from this test are presented in Table 2.

Table 2 shows that there is a significant difference between the pretest scores and posttest scores of the control group, as indicated by computed p-value ( $<$ 0.0001), which is lower than the significance level alpha (0.05). With this result, one should reject the null hypothesis $H_{o}$, and accept the alternative hypothesis $H_{a}$. Therefore, it can be said that the conventional method of teaching can increase the performance level of students in Physics class.

3) Difference between the Pretest and Posttest Scores of the Experimental Group

To determine the effectiveness of the Computer-Assisted Instruction, the difference between the pretest and posttest scores of the experimental group was statistically tested with the Mann-Whitney test. Findings obtained from this test are presented in Table 3.

Table 3 shows that there is a significant difference between the pretest scores and posttest scores of the experimental group, as indicated by computed p-value $(<0.0001)$, which is lower than the significance level alpha (0.05). With this result, one should reject the null hypothesis $H_{o}$, and accept the alternative hypothesis $H_{a}$. Therefore, it can be said that the Computer-Assisted Instruction (CAI) can increase the performance level of students in physics class.

4) Difference in the Mean Gain Scores of the Experimental Group and Control Group

To statistically determine the difference in the gain scores of the Computer-Assisted Instruction (CAI) and conventional method, the $Z$ test was used. The result of the $Z$ test is presented in Table 4.

Table 4 shows that there is no significant difference between the mean gain scores of the experimental and control groups since the computed p-value (0.609) is greater than the significance level alpha (0.05). Therefore, one cannot reject the null hypothesis $H_{o}$. This means that after instruction, students taught using Computer-Assisted Instruction (CAI) and the conventional method of teaching have the same performance level.

In Figure 1, the mean gain level of the experimental group $\bar{x}_{\text {pre }}=25.988$; $\bar{x}_{\text {post }}=34.950$ scored higher than the control group $\bar{x}_{\text {pre }}=24.675 ; \bar{x}_{\text {post }}=34.091$. However, statistical analysis shows that this advantage in gain level is not significant ( $p$-value $=0.609, \alpha=0.05$ ). The non-significant difference in the effect of the CAI and conventional method may be attributed to the mode of the delivery of the computer-aided instruction. 
Table 1. Difference in the pretest scores of experimental and control groups.

\begin{tabular}{ccccccc}
\hline Groups & $\begin{array}{c}\text { Number of } \\
\text { Students }\end{array}$ & Mean & $\begin{array}{c}\text { Standard } \\
\text { Deviation }\end{array}$ & $\begin{array}{c}\text { Test } \\
\text { Stat }\end{array}$ & p-value & Remarks \\
\hline $\begin{array}{c}\text { Computer-Assisted } \\
\text { Instruction } \\
\text { (Experimental) }\end{array}$ & 80 & 25.99 & 4.99 & & & \\
$\begin{array}{c}\text { Conventional Method } \\
(\text { Control })\end{array}$ & 77 & 24.68 & 6.63 & & & \\
\hline
\end{tabular}

Table 2. Difference in the pretest and posttest scores of the control group.

\begin{tabular}{ccccccc}
\hline $\begin{array}{c}\text { Conventional Method } \\
\text { (Control) }\end{array}$ & $\begin{array}{c}\text { Number of } \\
\text { Students }\end{array}$ & Mean & $\begin{array}{c}\text { Standard } \\
\text { Deviation }\end{array}$ & Test Stat & p-value & Remarks \\
\hline Pretest & 77 & 24.68 & 6.63 & 624.000 & $<0.0001$ Significant \\
Posttest & 77 & 34.09 & 4.11 & & \\
\hline
\end{tabular}

Table 3. Difference in the pretest and posttest scores of the experimental group.

\begin{tabular}{cccccc}
\hline $\begin{array}{c}\text { Computer-Assisted } \\
\text { Instruction } \\
\text { (Experimental) }\end{array}$ & $\begin{array}{c}\text { Number of } \\
\text { Students }\end{array}$ & Mean & $\begin{array}{c}\text { Standard } \\
\text { Deviation }\end{array}$ & $\begin{array}{c}\text { Test } \\
\text { Stat }\end{array}$ & p-value Remarks \\
\hline Pretest & 80 & 25.99 & 4.99 & & \\
Posttest & 80 & 34.95 & 3.82 & & \\
\hline
\end{tabular}

Table 4. Difference in the mean gain scores of the experimental and control group.

\begin{tabular}{ccccccc}
\hline Groups & $\begin{array}{c}\text { Number of } \\
\text { Students }\end{array}$ & $\begin{array}{c}\text { Mean Gain } \\
\text { Scores }\end{array}$ & $\begin{array}{c}\text { Standard } \\
\text { Deviation }\end{array}$ & $\begin{array}{c}\text { Test } \\
\text { Stat }\end{array}$ & p-value & Remarks \\
\hline $\begin{array}{c}\text { Computer-Assisted } \\
\text { Instruction } \\
\text { (Experimental) }\end{array}$ & 80 & 8.96 & 4.86 & & & Not \\
$\begin{array}{c}\text { Conventional Method } \\
\text { (Control) }\end{array}$ & 77 & 9.42 & 6.15 & & & \\
\hline
\end{tabular}

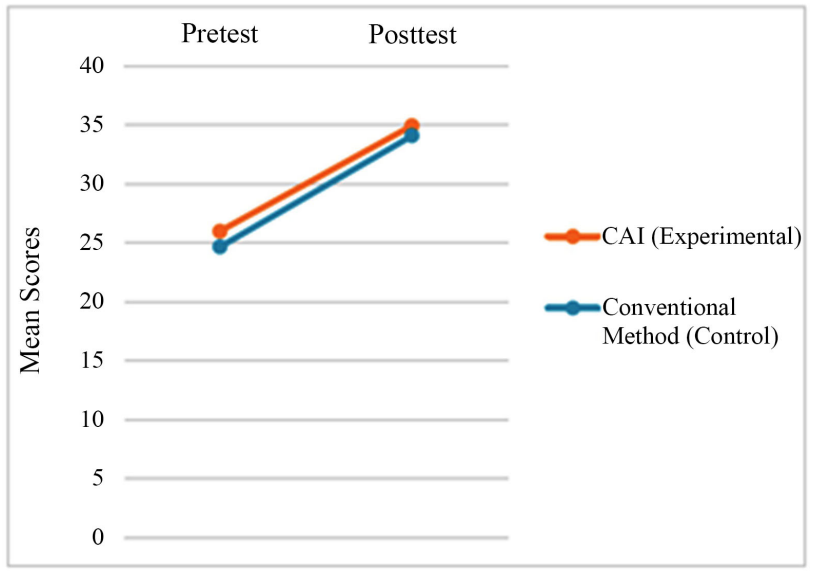

Figure 1. Pretest and posttest mean scores of experimental and control groups. 
In this study, the Computer-Assisted Instruction was used through a teacher-directed method which means that accessing the blog for online reading was teacher-guided and students were not allowed to browse other websites during the Online Reading sessions. Also, there were only four (4) simulations used during the course of study, and these simulations were used as overhead presentations during direct instructions or lecture-discussions. These simulations were simply projected on wide screens, and students were not given an opportunity to manipulate variables on the simulations. However, they were given an option to access simulations at home. CAI tools in this research were simply used as a substitute for the existing technology such as PowerPoint presentation to blackboard and blog articles to the textbook, respectively. Hence, using CAI tools only as a substitute for existing teaching tools in a non-interactive manner does not have a significant effect on instruction.

\subsection{Summary of Findings}

The following were the findings of the study: 1) At the start of the study, the control and experimental groups have the same level of performance in the Physics class; 2) The conventional method of teaching is effective in increasing the level of academic performance of students in the control group; 3) The Computer-Assisted Instruction is effective in increasing the level of academic performance of students in the experimental group; and 4) The use of CAI did not yield any significant difference on the academic achievement of students in Physics when compared to that of the conventional method of teaching.

The findings in this study may not be parallel to the popular results of related studies and of the vast literature, but this outcome may be attributed to some limitations of the study which includes the duration and frequency of CAI usage, type of CAI tool and modality utilized, and age and type of learners under study.

The duration of the study lasted for five weeks, and the exposure of students

to CAI involved five online reading sessions and four simulations delivered as overheads. In some studies (Pelones, 2003 [16]; Bayraktar, 2002 [18]), the limited time frame of the investigation was identified as the reason for the non-significant difference in the effect of CAI when compared to traditional teaching method in the academic achievement of learners.

In this research, simulations and teacher-directed discovery (online reading) were utilized as tools and modalities for the delivery of CAI for secondary school students from heterogeneous classes. Although students manipulate computers and learn at their own pace during online reading sessions, this is marginal compared to the time spent in teacher-directed instruction.

In addition, the age and homogeneity or heterogeneity of learners of the experimental and control groups may have influenced the result. Some studies reported that the effectiveness of simulations is diminished as learners mature. Discovery mode of CAI, which includes accessing online resources and reading, is also fitted to mature and independent learners (Kausar et al., 2008 [19]; Kulik et al., 1985 [20]). Since some studies show that the effectiveness of CAI depends 
on age groups and types of students, it is imperative to consider these factors in furthering the study.

\subsection{Conclusions}

Both the Computer-Assisted Instruction and conventional method are effective approaches in teaching Physics to secondary school students as indicated by the higher posttest than pretest scores. Therefore, CAI could still be used as an alternative teaching method, and the utilization CAI tool as supplementary material in instruction could be helpful.

However, the use of CAI did not yield any significant effect on the academic achievement of students in physics when compared to that of the conventional method of teaching. Thus, the impact of CAI may vary depending on the manner at which it was utilized. If CAI is simply used as a tool for direct instruction or a substitute for traditional instructional materials, it does not significantly differ when compared to the effect of the conventional method of teaching to student performance.

\section{Acknowledgements}

The researcher wishes to extend her most sincere gratitude to Dr. Sergio P. Revuelta, of Mindanao State University-GSC Graduate School, her Thesis adviser and to Ms. Kathy Long, Ms. Laura Scudder and the rest of the FOSS team for providing the consent to use the FOSS Module on Electricity and Magnetism.

\section{Conflicts of Interest}

The author declares no conflicts of interest regarding the publication of this paper.

\section{References}

[1] Martin, M., Mullis, I., Foy, P. and Stanco, G. (2012) TIMSS 2011 International Results in Science. TIMSS \& PIRLS International Study Center, Lynch School of Education, Boston College, Boston. http://timssandpirls.bc.edu/timss2011/downloads/T11_IR_Science_FullBook.pdf

[2] OECD (2018) PISA 2015 Results in Focus [Ebook]. https://www.oecd.org/pisa/pisa-2015-results-in-focus.pdf

[3] TIMSS 2015 (2019) International Reports. Timss2015.org. http://timss2015.org/advanced/timss-advanced-2015/physics/student-achievement/ achievement-of-2015-physics-cohort-at-the-eighth-and-fourth-grades

[4] Bao, L. and Koenig, K. (2019) Physics Education Research for 21st Century Learning. Disciplinary and Interdisciplinary Science Education Research, 1, Article No. 2. https://doi.org/10.1186/s43031-019-0007-8

[5] Beichner, R. (2009) An Introduction to Physics Education Research. https://www.researchgate.net/publication/237064083_An_Introduction_to_Physics Education_Research

[6] May, D.B. (2002) How Are Learning Physics and Student Beliefs about Learning Physics Connected? Measuring Epistemological Self-Reflection in an Introductory 
Course and Investigating Its Relationship to Conceptual Learning. Proquest Digital Dissertations.

[7] McGill Faculty of Science (2009) Physics Education Research (PER).

http://www.mcgill.ca/science/tpulse/resources/physics/52

[8] Freedman, R.A. (1996) Challenges in Teaching and Learning Introductory Physics. http://web.physics.ucsb.edu/ airboy/challenge.html https://doi.org/10.1007/978-1-4613-0411-1_26

[9] Kara, I. and Kahraman, O. (2008) The Effect of Computer Assisted Instruction on the Achievement of Students on the Instruction of Physics Topic of 7th Grade Science Course at a Primary School. Journal of Applied Sciences, 8, 1067-1072. http://scialert.net/qredirect.php?doi=jas.2008.1067.1072\&linkid=pdf https://doi.org/10.3923/jas.2008.1067.1072

[10] Christmann, E.P. and Badgett, J.L. (2000) The Comparative Effectiveness of CAI on Collegiate Academic Performance. Journal of Computing in Higher Education, 11, 91-103. https://doi.org/10.1007/BF02940892

[11] Vernadakis, N., Avgerinos, A., Tsitskari, E. and Zachopoulou, E. (2006) The Use of Computer Assisted Instruction in Preschool Education: Making Teaching Meaningful. Early Childhood Education Journal, 33, 99-104. https://doi.org/10.1007/s10643-005-0026-2

[12] Camnalbur, M. and Erdogan, Y. (2008) A Meta Analysis on the Effectiveness of Computer-Assisted Instruction: Turkey Sample. Educational Sciences: Theory \& Practice, 8, 497-505.

http://www.academia.edu/1321855/A_Meta_Analysis_on_the_Effectiveness_of_Co mputer-Assisted_Instruction_Turkey_Sample

[13] Alegre, C.C. (2012) Computer-Aided Instructional Tool in Linear Equation in Two Variables. Dissertation, Notre Dame of Marbel University, Koronadal City.

[14] Sumadic, A.C. (2012) Computer-Assisted Instruction sa Filipino sa Unang Taon sa Sekundarya sa Konteksto ng Understanding by Design. Master's Thesis, Notre Dame of Marbel University, Koronadal City.

[15] Guerrero, J. (2009) Computer-Assisted Demonstration Kit in Mechanics. Dissertation, Notre Dame of Marbel University, Koronadal City.

[16] Pelones, M.T. (2003) Computer-Aided Cooperative Learning Approach in Math: Its Effect on the Academic Performance and Change in Math Perception of Fourth Year Students in General Santos City High School. Master's Thesis, Mindanao State University, Marawi.

[17] Diculen, L. (1999) Design, Development and Summative Evaluation of Computer-Assisted Instruction (CAI) Modules on Selected Topics in High School Physics. Dissertation, De La Salle University, Manila.

[18] Bayraktar, S. (2002) A Meta-Analysis of the Effectiveness of Computer-Assisted Instruction in Science Education. Journal of Research on Technology in Education, 34, 173-188. https://doi.org/10.1080/15391523.2001.10782344

[19] Kausar, T., Choudhry, B. and Gujjar, A. (2008) A Comparative Study to Evaluate the Effectiveness of Computer Assisted Instruction (CAI) versus Classroom Lecture (CRL) for Computer Science at ICS Level. The Turkish Online Journal of Educational Technology, 7, 19-28. http://www.tojet.net/articles/v7i4/742.pdf

[20] Kulik, J., Kulik, C. and Bangert-Drowns, R. (1985) Effectiveness of Computer-Based Education in Elementary Schools. Computer in Human Behavior, 1, 59-74.

http://deepblue.lib.umich.edu/bitstream/2027.42/25814/1/0000377.pdf https://doi.org/10.1016/0747-5632(85)90007-X 